\title{
EBUS-TBNA Can Distinguish Sarcoid-Like Side Effect of Nivolumab Treatment from Tumor Progression in Non-Small Cell Lung Cancer
}

\author{
Ségolène Lainez ${ }^{a} \quad$ Claire Tissot $^{a} \quad$ Michèle Cottier $^{b} \quad$ Jean-Michel Vergnon ${ }^{a}$ \\ Departments of a Chest Diseases and Thoracic Oncology, and b ${ }^{b}$ Cytology, Hôpital Nord, CHU de Saint-Étienne, \\ Saint-Étienne, France
}

\section{Established Facts}

- Immunotherapy in cancer is known to generate sarcoid-like reaction. The difficulty is to make the differential diagnosis with cancer progression when it appears in lymph nodes.

\section{Novel Insights}

- Clinicians have to be aware of the necessity to make the diagnosis of mediastinal sarcoid-like reaction using EBUS-TBNA not to be misled by pseudoprogression and to continue immunotherapy if it is effective.

\section{Keywords}

Lung cancer · EBUS-TBNA · Nivolumab · Mediastinal lymph nodes

\begin{abstract}
With the expansion of immunotherapy in the treatment of lung cancer, clinicians have to face new clinical pictures and adapt their practice. We report the case of a 69-year-old man diagnosed with non-small cell lung cancer using endobronchial ultrasound-guided transbronchial needle aspiration (EBUS-TBNA) and treated with nivolumab as second-line therapy. After 8 injections of nivolumab, a new CT and PET scan revealed massive growth and increase in metabolism of hilar and mediastinal lymph nodes, whereas the size and
\end{abstract}

(c) 2017 S. Karger AG, Basel

E-Mail karger@karger.com www.karger.com/res metabolism of the left upper lobe lesion were reduced. A new EBUS-TBNA was thus performed and showed an epithelioid cell reaction compatible with sarcoidosis in the 3 punctured lymph nodes (stations $4 \mathrm{R}, 11 \mathrm{~L}, 7$ ). In the absence of cancer evolution, nivolumab was continued, and the CT after the twelfth injection showed stability.

(c) 2017 S. Karger AG, Base

\section{Introduction}

Nivolumab, a fully human IgG4 against programmed death 1 (PD-1), has been used in pulmonology since the end of 2015 [1]. It improves the prognosis of patients with advanced non-small cell lung cancer when it is used as a 

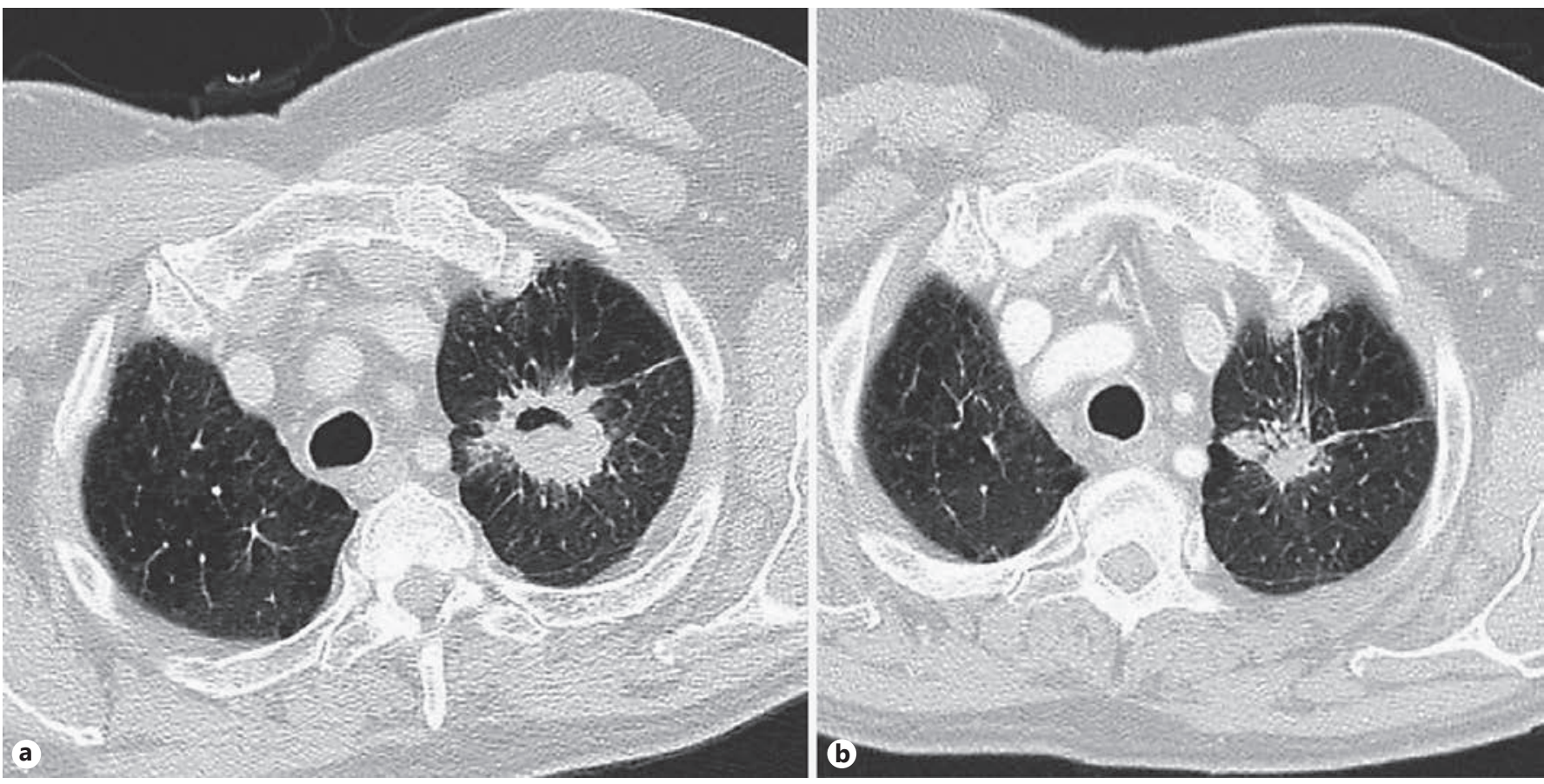

Fig. 1. CT cross sections showing the malignant mass. a July 2016, before nivolumab treatment. b November 2016, after 8 nivolumab injections: dramatic decrease in tumor size (from 29.8 to $3.1 \mathrm{~cm}^{3}$ ).

second-line therapy [2]. To treat melanoma, dermatologists have already been using immunotherapy since 2011 with ipilimumab, and since 2015 with nivolumab.

Immunotherapy is associated with a unique set of toxicities termed immune-related adverse events, which are different from toxicities observed with conventional cytotoxic chemotherapy [3]. These adverse effects are found in patients treated for early-stage lung cancer. This case illustrates pseudoprogression by lymph node sarcoid-like reaction [4-8]. This form prompts further explorations not to disregard any cancer evolution.

\section{Case Report}

In August 2015, a 69-year-old patient was diagnosed with a lung mass in the left upper lobe. The patient was a former smoker with a history of 35 pack-year tobacco use. The PET scan showed an intense hypermetabolism of the parenchymal mass (SUV 18.6), of a hilar adenopathy (11L: SUV 15), and of mediastinal adenopathies (SUV up to 12.8 in station $4 \mathrm{R}$ and in station 7).

The diagnosis was obtained by endobronchial ultrasoundguided transbronchial needle aspiration (EBUS-TBNA) [9-11]. All stations $(4 \mathrm{R}, 7,11 \mathrm{~L})$ were sampled, but only station 7 was invaded by non-small cell carcinoma metastasis. It was not possible to distinguish between adenocarcinoma or epidermoid carcinoma. Immunostaining was not performed because the sample was too limited. Radiochemotherapy was first planned; thus the histological type was not explored further. But secondly, radiotherapy was canceled because of the too large volume of the lesion.

He received a first-line treatment with 5 cycles of cisplatinvinorelbine until December 2015. Concomitant mediastinal and pulmonary radiotherapy was contraindicated because of the spread of the lesion. The CT scan demonstrated a significant reduction of the tumor. At this time, chemotherapy was stopped. During the follow-up, the body scan, performed in July 2016, showed a new growth of the tumor mass, and a right elbow bone metastasis was discovered with a new PET scan. At that time, the patient refused the biopsy of the lesion of his right elbow which would have enabled a search for mutations.

A second-line treatment was thus proposed with nivolumab 3 $\mathrm{mg} / \mathrm{kg}$. After 4 injections, spaced between 2 weeks apart, the CT scan showed an obvious effect on the mass which was reduced by $50 \%$ in September 2016. The following 4 injections were well tolerated. The CT scan showed a reduction in tumor size (Fig. 1) contrasting with a growth of mediastinal lymph nodes confirmed by a new PET scan (Fig. 2).

A new EBUS exploration was done in January 2017 to understand the dissociation between lymph nodes and tumor evolution and to obtain new malignant tissue in order to exclude any mutation of the malignant cells. All stations $(4 \mathrm{R}, 7,11 \mathrm{~L})$ were again sampled in January 2017. The cytological results found typical granulomatous reaction in each punctured lymph node without tumoral involvement (Fig. 3). In the absence of cancer progression, we decided to continue with nivolumab as its effect on the lung mass was evident. After 4 additional injections, the CT showed that the disease was stable. 
Fig. 2. PET scan in July 2016, before the first nivolumab injection (a), and in November 2016, after 8 nivolumab injections (b). The growth of multiple bilateral hypermetabolic mediastinal lymph nodes contrasts with the obvious reduction in the metabolism of the left upper lobe tumor (SUV 5.3 vs. SUV 15 in July 2016). Also note the decrease in metabolism in the right elbow metastatic site.

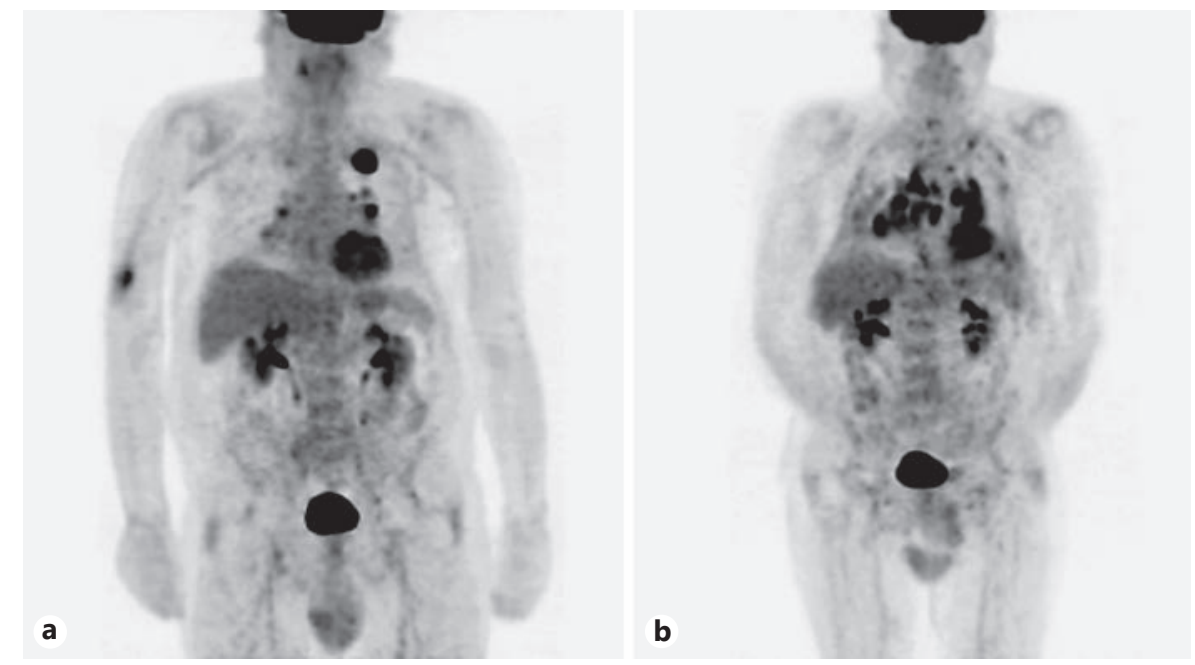

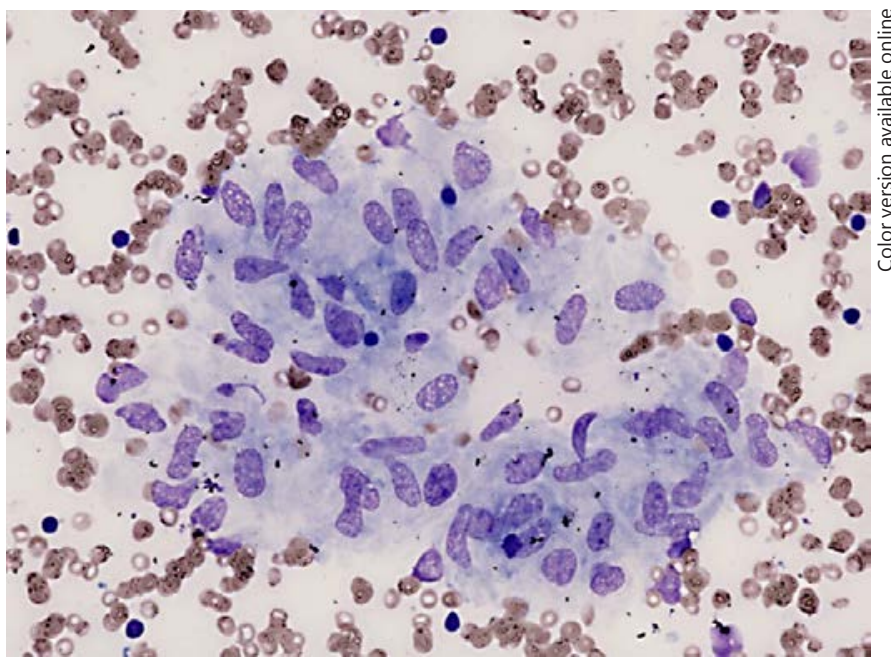

Fig. 3. May-Grünwald-Giemsa-stained smear of a lymph node puncture showing a cluster of epithelioid cells. Magnification, $\times 400$.

\section{Discussion}

This case shows a sarcoid-like reaction with nivolumab in a patient suffering from lung cancer. Although EBUS-TBNA provides only a cytological evaluation, its advantages for the diagnosis of lung cancer and sarcoidosis have been largely proven [9-14]. Interestingly in our study, the diagnoses of cancer and later of sarcoid-like reaction were both made using EBUS-TBNA and both in the same punctured lymph node. Consequently, the quality of the comparison is high. It is also important to note that the sarcoid-like reaction was found not only in the previously invaded station 7 , but also in all punctured nodes, which represents a systemic process.

Moreover, nivolumab, and even more ipilimumab, have been described to generate a sarcoid-like reaction. This reaction has been well documented in melanoma [3-8] but on rare occasion also in lung carcinoma. Concerning the few cases of lung cancer, none of them showed clear lymph node progression with sarcoid-like reaction, but rather a cutaneous form or unclear diagnosis $[15,16]$. In this case, the differential diagnosis is more challenging and has a greater impact on treatment strategy.

Anti-PD-1 inhibitors in patients with advanced nonsmall cell lung cancer are becoming more and more relevant as second-line treatment and may become firstline treatment in the future. Clinicians should be aware of these potential associated immune-related adverse events.

To conclude, patients treated by immunotherapy for lung cancer should be considered at risk of sarcoid-like reaction that mimics tumor progression. Therefore, in case of lymph node progression on $\mathrm{CT}$, the diagnosis must be proven by EBUS-TBNA.

References

1 Romero D: Nivolumab - an effective secondline treatment for NSCLC. Nat Rev Clin Oncol DOI: 10.1038/nrclinonc.2015.184.

2 Ellis PM, Vella ET, Yung YC: Immune checkpoint inhibitors for patients with advanced non-small-cell lung cancer: a systematic review. Clin Lung Cancer DOI: 10.1016/j.cllc. 2017.02.001. 
3 Abdel-Wahab N, Shah M, Suarez-Almazor ME: Adverse events associated with immune checkpoint blockade in patients with cancer: a systematic review of case reports. PLoS One DOI: 10.1371/journal.pone.0160221.

4 Reuss JE, Kunk PR, Stowman AM, Gru AA, Slingluff CL Jr, Gaughan EM: Sarcoidosis in the setting of combination ipilimumab and nivolumab immunotherapy: a case report \& review of the literature. J Immunother Cancer 2016;4:94.

5 Montaudie H, J Pradelli J, Passeron T, Lacour J-P, Leroy S: Pulmonary sarcoid-like granulomatosis induced by nivolumab. Br J Dermatol 2017;176:1060-1063.

6 Danlos FX, Pagès C, Baroudjian B, Vercellino L, Battistella M, Mimoun M, Jebali M, Bagot M, Tazi A, Lebbé C: Nivolumab-induced sarcoid-like: granulomatous reaction in a patient with advanced melanoma. Chest 2016;149: e133-e136.

7 Suozzi KC, Stahl M, Ko CJ, Chiang A, Gettinger SN, Siegel MD, Bunick CG: Immunerelated sarcoidosis observed in combination ipilimumab and nivolumab therapy. JAAD Case Rep 2016;2:264-268.
8 Firwana B, Ravilla R, Raval M, Hutchins L, Mahmoud F: Sarcoidosis-like syndrome and lymphadenopathy due to checkpoint inhibitors. J Oncol Pharm Pract DOI: 10.1177/ 1078155216667635.

9 Um SW, Kim HK, Jung SH, Han J, Lee KJ, Park HY, Choi YS, Shim YM, Ahn MJ, Park K, Ahn YC, Choi JY, Lee KS, Suh GY, Chung MP, Kwon OJ, Kim J, Kim H: Endobronchial ultrasound versus mediastinoscopy for mediastinal nodal staging of non-small-cell lung cancer. J Thorac Oncol 2015;10:331-337.

10 Sehgal IS, Dhooria S, Aggarwal AN, Behera D, Agarwal R: Endosonography versus mediastinoscopy in mediastinal staging of lung cancer: systematic review and meta-analysis. Ann Thorac Surg 2016;102:1747-1755.

11 Dong X, Qiu X, Liu Q, Jia J: Endobronchial ultrasound-guided transbronchial needle aspiration in the mediastinal staging of nonsmall cell lung cancer: a meta-analysis. Ann Thorac Surg 2013;96:1507.

12 Gupta D, Dadhwal DS, Agarwal R, Gupta N Bal A, Aggarwal AN: Endobronchial ultrasound-guided transbronchial needle aspiration vs conventional transbronchial needle aspiration in the diagnosis of sarcoidosis. Chest 2014;146:547-556
13 Agarwal R, Srinivasan A, Aggarwal AN, Gupta D: Efficacy and safety of convex probe EBUS-TBNA in sarcoidosis: a systematic review and meta analysis. Respir Med 2012;106: 883-892.

14 von Bartheld MB, Dekkers OM, Szlubowski A, Eberhardt R, Herth FJ, in 't Veen JC, de Jong YP, van der Heijden EH, Tournoy KG, Claussen M, van den Blink B, Shah PL, Zoumot Z, Clementsen P, Porsbjerg C, Mauad T, Bernardi FD, van Zwet EW, Rabe KF, Annema JT: Endosonography vs conventional bronchoscopy for the diagnosis of sarcoidosis: the GRANULOMA Randomized Clinical Trial. JAMA 2013;309:2457-2464.

15 Birnbaum MR, Ma MW, Fleisig S, Packer S, Amin BD, Jacobson M, McLellan BN: Nivolumab-related cutaneous sarcoidosis in a patient with lung adenocarcinoma. JAAD Case Rep 2017;3:208-211.

16 Izumida T, Kawagishi Y, Tsuji H: Pseudoprogression in lung adenocarcinoma during treatment with nivolumab. BMJ Case Rep DOI: $10.1136 / \mathrm{bcr}-2017-219919$. 